\title{
Exploring the utility of quantitative network design in evaluating Arctic sea ice thickness sampling strategies
}

\author{
T. Kaminski ${ }^{1, a}$, F. Kauker ${ }^{2}$, H. Eicken ${ }^{3}$, and M. Karcher ${ }^{2}$ \\ ${ }^{1}$ The Inversion Lab, Martinistr. 21, 20251 Hamburg, Germany \\ ${ }^{2}$ OASys, Lerchenstraße 28a, 22767 Hamburg, Germany \\ ${ }^{3}$ Geophysical Institute and International Arctic Research Center, University of Alaska Fairbanks, P.O. Box 757320, \\ Fairbanks, AK 99775-7320, USA \\ a formerly at: FastOpt, Hamburg, Germany \\ Correspondence to: T. Kaminski (thomas.kaminski@Inversion-Lab.com)
}

Received: 3 March 2015 - Published in The Cryosphere Discuss.: 19 March 2015

Revised: 24 July 2015 - Accepted: 9 August 2015 - Published: 27 August 2015

\begin{abstract}
We present a quantitative network design (QND) study of the Arctic sea ice-ocean system using a software tool that can evaluate hypothetical observational networks in a variational data assimilation system. For a demonstration, we evaluate two idealised flight transects derived from NASA's Operation IceBridge airborne ice surveys in terms of their potential to improve 10-day to 5-month sea ice forecasts. As target regions for the forecasts we select the Chukchi Sea, an area particularly relevant for maritime traffic and offshore resource exploration, as well as two areas related to the Barnett ice severity index (BSI), a standard measure of shipping conditions along the Alaskan coast that is routinely issued by ice services. Our analysis quantifies the benefits of sampling upstream of the target area and of reducing the sampling uncertainty. We demonstrate how observations of sea ice and snow thickness can constrain ice and snow variables in a target region and quantify the complementarity of combining two flight transects. We further quantify the benefit of improved atmospheric forecasts and a well-calibrated model.
\end{abstract}

\section{Introduction}

The Arctic climate system is undergoing a rapid transformation. Such changes, in particular reductions in sea ice extent, are impacting coastal communities and ecosystems and are enhancing the potential for resource extraction and shipping. In this context, the ability to anticipate anomalous ice conditions and in particular sea ice hazards associated with seasonal-scale and short-term variations in ice cover is essential. For example, in 2012, despite a long-term trend of greatly reduced ice cover in the Chukchi Sea off Alaska's coast, ice incursions and associated hazards led to early termination of the resource exploration season (Eicken and Mahoney, 2015). In this context, high-quality predictions of the ice conditions are of paramount interest. Such predictions are typically performed by numerical models of the sea iceocean system. These models are based on fundamental equations that govern the processes controlling ice conditions. Uncertainty in model predictions arises from four sources: first, there is uncertainty in the atmospheric forcing data (such as wind velocity or temperature) driving the relevant processes. Second, there is uncertainty regarding the formulation of individual processes and their numerical implementation (structural uncertainty). Third, there are uncertain constants (process parameters) in the formulation of these processes (parametric uncertainty). Fourth, there is uncertainty about the state of the system at the beginning of the simulation (initial state).

Observational information can be exploited to reduce these uncertainties. Currently there are several initiatives underway to extend and consolidate the observational network of the Arctic climate system, ranging, e.g., from the International Arctic Systems for Observing the Atmosphere and Surface (IASOAS) to the Global Terrestrial Network for Permafrost (GTN-P). Ideally, all observational data streams are interpreted simultaneously with the process information provided 
by the model to yield a consistent picture of the state of the Arctic system that balances all the observational constraints, taking into account the respective uncertainty ranges. Data assimilation systems that tie into prognostic models of the Arctic system are ideal tools for this integration task because they allow a variety of observations to be combined with the simulated dynamics of a model.

Quantitative network design (QND) is a technique that aims to design an observational network with optimal performance. The approach is based on work by Hardt and Scherbaum (1994), who optimised the station locations for a seismographic network. It was first applied to the climate system by Rayner et al. (1996), who optimised the spatial distribution of atmospheric measurements of carbon dioxide. A series of QND studies (Rayner and O'Brien, 2001; O'Brien and Rayner, 2002; Rayner et al., 2002) demonstrated the feasibility of the network design approach and delineated the requirements for the implementation of the first satellite mission designed to observe atmospheric $\mathrm{CO}_{2}$ from space (the Orbiting Carbon Observatory; Crisp et al., 2004). Since then, the technique has been routinely applied in the design of $\mathrm{CO}_{2}$ space missions (Patra et al., 2003; Kadygrov et al., 2009; Kaminski et al., 2010; Rayner et al., 2014) and the extension of the in situ sampling network for atmospheric carbon dioxide. Recent examples focus on in situ networks over Australia (Ziehn et al., 2014) and South Africa (Nickless et al., 2014). The design of a combined atmospheric and terrestrial network of the European carbon cycle is addressed by Kaminski et al. (2012).

The present study applies the QND concept to the Arctic sea ice-ocean system. It describes the Arctic Observational Network Design (AOND) system, a tool that can evaluate the performance of observational networks comprising a range of different data streams. We illustrate the utility of the tool by evaluating the relative merits of alternate airborne transects within the context of NASA's Operation IceBridge (Richter-Menge and Farrell, 2013; Kurtz et al., 2013a), assessing their potential to improve ice forecasts in the Chukchi Sea and along the Alaskan coast.

\section{Methods}

Our AOND system evaluates observational networks in terms of their impact on target quantities in a data assimilation system. Both the data assimilation system and the AOND system are built around the same model of the Arctic sea ice-ocean system. Below, we first present the model, then the assimilation system and finally the QND approach that operates on top of this model.

\subsection{NAOSIM}

The model used for the present analysis is the coupled sea ice-ocean model NAOSIM (North Atlantic/Arctic Ocean
Sea Ice Model; Kauker et al., 2003). NAOSIM is based on version 2 of the Modular Ocean Model (MOM-2) of the Geophysical Fluid Dynamics Laboratory. The version of NAOSIM used here has a horizontal grid spacing of $0.5^{\circ}$ on a rotated spherical grid. The rotation maps the $30^{\circ} \mathrm{W}$ meridian onto the Equator and the North Pole onto $0^{\circ}$ E. Hence, the model's $x$ and $y$ directions are different from the zonal and meridional directions, and the grid is almost equidistant. In the vertical it resolves 20 levels, their spacing increasing with depth from 20 to $480 \mathrm{~m}$. At the southern boundary (near $50^{\circ}$ N) an open boundary condition has been implemented following Stevens (1991), allowing the outflow of tracers and the radiation of waves. The other boundaries are treated as closed walls. At the open boundary the barotropic transport is prescribed from a coarser-resolution version of the model that covers the whole Atlantic northward of $20^{\circ} \mathrm{S}$ (Köberle and Gerdes, 2003).

A dynamic-thermodynamic sea ice model with a viscousplastic rheology (Hibler, 1979) is coupled to the ocean model. The prognostic variables of the sea ice model are ice thickness, snow depth, and ice concentration. Ice drift is calculated diagnostically from the momentum balance. Snow depth and ice thickness are mean quantities over a grid box. The thermodynamic evolution of the ice is described by an energy balance of the ocean mixed layer following Parkinson and Washington (1979). Freezing and melting are calculated by solving the energy budget equation for a single ice layer with a snow layer. When atmospheric temperatures are below the freezing point, precipitation is added to the snow mass; otherwise it is added to the ocean. The snow layer is advected jointly with the ice layer. The surface heat flux is calculated through a standard bulk formula approach using prescribed atmospheric data and sea surface temperature predicted by the ocean model. Owing to its low heat conductivity, the snow layer has a high impact on the simulated energy balance (Castro-Morales et al., 2014). The sea ice model is formulated on the ocean model grid and uses the same time step. The models are coupled following the procedure devised by Hibler and Bryan (1987).

Atmospheric forcing ( $10 \mathrm{~m}$ wind velocity, $2 \mathrm{~m}$ air temperature, $2 \mathrm{~m}$ dew point temperature, total precipitation, and total cloud cover) is taken from the National Centers for Environmental Prediction/National Center for Atmospheric Research (NCEP/NCAR) reanalysis (Kalnay et al., 1996). This study is based on a model integration from 1 April to 31 August 2007. The initial state of this integration is the final state of a hindcast from January 1948 to the end of March 2007, forced by NCEP/NCAR reanalyses and in turn initialised from Polar Science Center Hydrographic Climatology (PHC) data (Steele et al., 2001) (ocean temperature and salinity), zero ocean velocities and zero snow depth, a constant ice thickness of $2 \mathrm{~m}$ with $100 \%$ ice cover where the air temperature is below the freezing temperature of the ocean's top layer and zero ice drift. The model's process formulations depend on a number of uncertain parameters. Table 1 summarises at- 
Table 1. Control variables. Column 1 lists the quantities in the control vector; column 2 gives the abbreviation for each quantity; column 3 indicates whether the quantity is an atmospheric boundary (forcing, i.e. f) field, an initial field (i), or a process parameter (p); column 4 gives the name of each quantity; column 5 indicates (the standard deviation of) the prior uncertainty and the corresponding units and provides the magnitude of the parameter value in parenthesis, where applicable; and column 6 identifies the position of the quantity in the control vector - for initial and boundary values (which are differentiated by region) this position refers to the first region, while the following components of the control vector then cover regions 2 to 9.

\begin{tabular}{|c|c|c|c|c|c|}
\hline Index \# & Name & Type & Meaning & Prior uncertainty (value) & Start \\
\hline 1 & taux & $\mathrm{f}$ & wind stress model $x$ component & $0.02 \mathrm{Nm}^{2}$ & 1 \\
\hline 2 & tauy & $\mathrm{f}$ & wind stress model $y$ component & $0.02 \mathrm{Nm}^{2}$ & 10 \\
\hline 3 & $2 \mathrm{mT}$ & $\mathrm{f}$ & $2 \mathrm{~m}$ air temperature & $1.2 \mathrm{~K}$ & 19 \\
\hline 4 & DewT & $\mathrm{f}$ & dew pointe temperature & $1.1 \mathrm{~K}$ & 28 \\
\hline 5 & cld & $\mathrm{f}$ & cloud cover & 0.07 & 37 \\
\hline 6 & precip & $\mathrm{f}$ & total precipitation & $0.4 \times 10^{-8} \mathrm{~ms}^{-1}$ & 46 \\
\hline 7 & scalwnd & $\mathrm{f}$ & scalar wind speed & $0.6 \mathrm{~ms}^{-1}$ & 55 \\
\hline 8 & kappa $_{m}$ & $\mathrm{p}$ & vertical viscosity coeff. & $0.1 \times 10^{-3}\left(1.0 \times 10^{-3}\right) \mathrm{m}^{2} \mathrm{~s}^{-1}$ & 64 \\
\hline 9 & kappa $_{h}$ & $\mathrm{p}$ & vertical diffusion coeff. & $1.0 \times 10^{-5}\left(1.0 \times 10^{-5}\right) \mathrm{m}^{2} \mathrm{~s}^{-1}$ & 65 \\
\hline 10 & cdbot & $\mathrm{p}$ & bottom drag coeff. & $0.5 \times 10^{-3}\left(1.2 \times 10^{-3}\right)$ & 66 \\
\hline 11 & temp $_{i}$ & $\mathrm{i}$ & initial ocean temperature & $0.5 \mathrm{~K}$ (vertically decreasing) & 67 \\
\hline 12 & salinity $_{i}$ & $\mathrm{i}$ & initial salinity & $0.5 \mathrm{psu}$ (vertically decreasing) & 76 \\
\hline 13 & pstar & $\mathrm{p}$ & ice strength & $10000(15000) \mathrm{Nm}$ & 85 \\
\hline 14 & cstar & $\mathrm{p}$ & ice strength depend. on ice conc. & $5.0(20.0)$ & 86 \\
\hline 15 & eccen & $\mathrm{p}$ & squared yield curve axis ratio & $0.5(2.0)$ & 87 \\
\hline 16 & gmin & $\mathrm{p}$ & regime plastic-linear viscous & $1.0 \times 10^{-9}\left(5.0 \times 10^{-9}\right)$ & 88 \\
\hline 17 & $h_{0}$ & $\mathrm{p}$ & lead closing & $1.0(0.5) \mathrm{m}$ & 89 \\
\hline 18 & cdwat & $\mathrm{p}$ & ocean drag coeff. & $2.0 \times 10^{-3}\left(5.5 \times 10^{-3}\right)$ & 90 \\
\hline 19 & cdwin & $\mathrm{p}$ & atmosphere drag coeff. & $\begin{array}{l}1.0 \times 10^{-3}\left(2.475 \times 10^{-3}\right) \\
(\text { absorbed in taux/y) }\end{array}$ & \\
\hline 20 & angwat & $\mathrm{p}$ & ice turning angle & $5.0^{\circ}\left(25.0^{\circ}\right)$ & 92 \\
\hline 21 & cdsens & $\mathrm{p}$ & sensible heat flux coeff. & $0.5 \times 10^{-3}\left(1.75 \times 10^{-3}\right)$ & 93 \\
\hline 22 & cdlat & $\mathrm{p}$ & latent heat flux coeff. & $0.5 \times 10^{-3}\left(1.75 \times 10^{-3}\right)$ & 94 \\
\hline 23 & albw & $\mathrm{p}$ & open water albedo & $0.05(0.1)$ & 95 \\
\hline 24 & albi & $\mathrm{p}$ & freezing ice albedo & $0.1(0.7)$ & 96 \\
\hline 25 & albm & $\mathrm{p}$ & melting ice albedo & $0.1(0.68)$ & 97 \\
\hline 26 & albsn & $\mathrm{p}$ & freezing snow albedo & $0.1(0.8)$ & 98 \\
\hline 27 & albsnm & $\mathrm{p}$ & melting snow albedo & $0.1(0.77)$ & 99 \\
\hline 28 & $h_{i}$ & $\mathrm{i}$ & initial ice thickness & $0.5 \mathrm{~m}$ & 100 \\
\hline 29 & $a_{i}$ & $\mathrm{i}$ & initial ice concentration & 0.1 & 109 \\
\hline 30 & $\mathrm{hsn}_{i}$ & $\mathrm{i}$ & initial snow thickness & $0.2 \mathrm{~m}$ & 118 \\
\hline
\end{tabular}

mospheric forcing fields and initial fields, and lists a subset of the model's relevant process parameters.

\subsection{Assimilation}

The variational assimilation system NAOSIMDAS (Kauker et al., 2009, 2010) operates through minimisation of a cost function that quantifies the fit to all observations plus the deviation from prior knowledge on a vector of control vari- ables $x$ :

$$
\begin{aligned}
& J(\boldsymbol{x})=\frac{1}{2}\left[(M(\boldsymbol{x})-\boldsymbol{d})^{\mathrm{T}} \mathbf{C}(d)^{-1}(M(\boldsymbol{x})-\boldsymbol{d})\right. \\
& \left.+\left(\boldsymbol{x}-\boldsymbol{x}_{0}\right)^{\mathrm{T}} \mathbf{C}\left(x_{0}\right)^{-1}\left(\boldsymbol{x}-\boldsymbol{x}_{0}\right)\right],
\end{aligned}
$$

where $M$ denotes the model, considered as a mapping from the control vector to observations; $\mathbf{d}$ the observations with data uncertainty covariance matrix $\mathbf{C}(d) ; \boldsymbol{x}_{0}$ the vector of prior values of the control variables with uncertainty covariance matrix $\mathbf{C}\left(x_{0}\right)$; and the superscript $\mathrm{T}$ is the transpose operator. The control variables are typically a combination of the initial state, the atmospheric forcing and the process parameters. The data uncertainty $\mathbf{C}(d)$ reflects the combined effect of observational $\mathbf{C}\left(d_{\text {obs }}\right)$ and model error $\mathbf{C}\left(d_{\bmod }\right)$ :

$\mathbf{C}(d)^{2}=\mathbf{C}\left(d_{\text {obs }}\right)^{2}+\mathbf{C}\left(d_{\text {mod }}\right)^{2}$. 
$\mathbf{C}\left(d_{\text {mod }}\right)$ captures all uncertainty in the simulation of the observations except for the uncertainty in the control vector because this fraction of the uncertainty is explicitly addressed by the assimilation procedure through correction of the control vector.

The control vector $\tilde{x}$ that minimises Eq. (1) achieves a balance between the observational constraints and the prior information. The minimum is determined through variation of the control vector (hence variational assimilation) comprising initial and boundary conditions and process parameters. In contrast to sequential assimilation approaches, which result in a sequence of corrections of the state predicted by the model, the variational approach guarantees full consistency with the dynamics imposed by the model, as it provides an entire trajectory through the state space of the model in response to the change in the control vector. In the case of our model this means that we infer a trajectory that assures conservation of mass, energy and momentum (except at the lateral domain boundaries). We note that, in this QND study, no minimisation of Eq. (1) is required.

\subsection{QND}

We provide a brief description of the methodological background for QND, which follows Kaminski and Rayner (2008). The approach is based on propagation of uncertainty from the data to a target quantity of interest. The target quantity may be any aspect (e.g. a prognostic or diagnostic variable or a process parameter) that can be extracted from a simulation with the underlying model, for example, the sea ice concentration integrated over a particular domain and time period.

QND proceeds in two steps. In the first step, the second derivative (Hessian) of the cost function (Eq. 1) is used to approximate the inverse of the covariance matrix $\mathbf{C}(x)$ of posterior uncertainty of the control vector, which quantifies the uncertainty ranges of the control variables that are consistent with uncertainties in the observations and the model. Denoting the linearisation of the model by $\mathbf{M}^{\prime}$, we can approximate this posterior uncertainty by

$\mathbf{C}(x)^{-1}=\mathbf{M}^{\prime \mathrm{T}} \mathbf{C}(d)^{-1} \mathbf{M}^{\prime}+\mathbf{C}\left(x_{0}\right)^{-1}$.

The first term on the right-hand side quantifies the observational impact which yields an uncertainty reduction with respect to the prior uncertainty (inverse of the second term).

When the prior uncertainty is already small, the second term is large, and a large observational impact is required to achieve a substantial uncertainty reduction. The observational impact is large when the observations are highly sensitive to changes in the control variables and when the data uncertainty is small. The first condition describes the relevance of the observation, and the second condition its quality.

In the second step, the linearisation $\mathbf{N}^{\prime}$ (Jacobian) of the model $N$ used as a mapping from the control vector to target quantities is employed to propagate the uncertainties in the

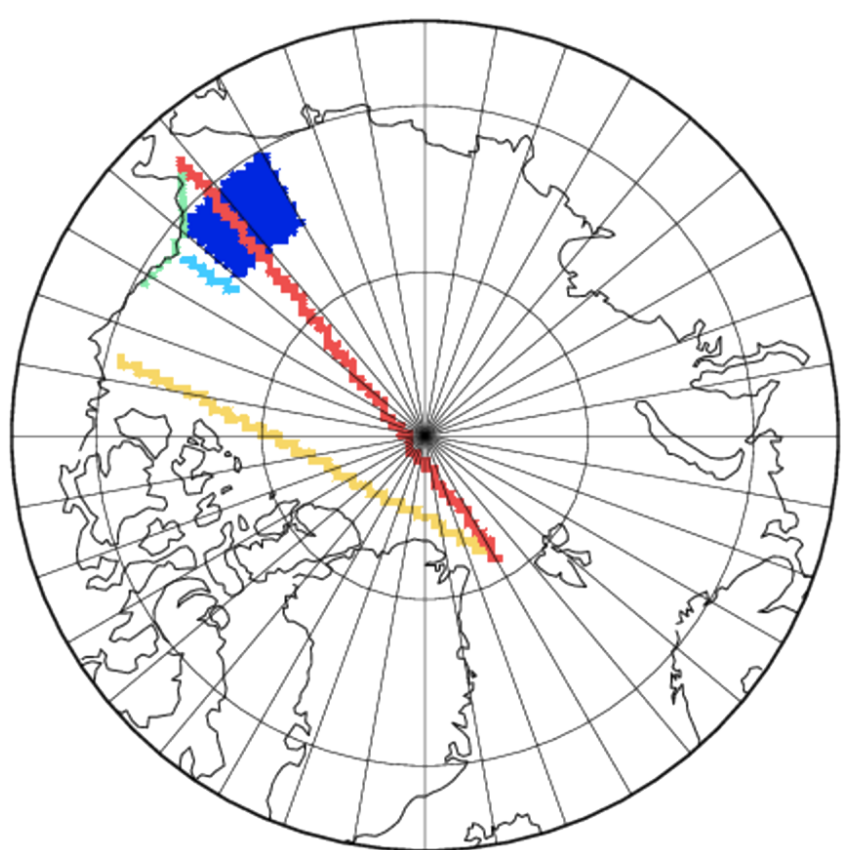

Figure 1. Target regions: Chukchi (dark blue); north of Barrow (NOB, light blue) Bering Strait to Prudhoe Bay (BS2PB, red). Flight transects: Chukchi to Fram $(\mathrm{C} 2 \mathrm{~F}$, red); Beaufort to Fram (B2F, yellow).

control vector forward to the uncertainty in a target quantity $\sigma(y)$ :

$\sigma(y)^{2}=\mathbf{N}^{\prime} \mathbf{C}(x) \mathbf{N}^{\prime T}+\sigma\left(y_{\bmod }\right)^{2}$.

If the model were perfect, $\sigma\left(y_{\text {mod }}\right)$ would be zero. In contrast, if the control variables were perfectly known, the first term on the right-hand side would be zero. Equation (4) relates the uncertainty in control space to uncertainty in a target quantity.

Evaluating Eq. (4) for the prior uncertainty $\mathbf{C}\left(x_{0}\right)$ instead of the posterior uncertainty $\mathbf{C}(x)$, i.e. for a case without observational constraint, yields a prior uncertainty for the target quantity:

$\sigma\left(y_{0}\right)^{2}=\mathbf{N}^{\prime} \mathbf{C}\left(x_{0}\right) \mathbf{N}^{\prime \mathrm{T}}+\sigma\left(y_{\bmod }\right)^{2}$.

We define the term uncertainty reduction relative to $\sigma\left(y_{0}\right)$, i.e. by

$\frac{\sigma\left(y_{0}\right)-\sigma(y)}{\sigma\left(y_{0}\right)}=1-\frac{\sigma(y)}{\sigma\left(y_{0}\right)}$.

For example, if $\sigma(y)$ is $90 \%$ of $\sigma\left(y_{0}\right)$, then the uncertainty reduction is $10 \%$; i.e. we have increased our knowledge on $y$ by 10 .

To reduce uncertainty for a target quantity, the observations need to reduce uncertainty in the sub-space of the control space that (through the matrix $N^{\prime}$ ) projects onto the target 


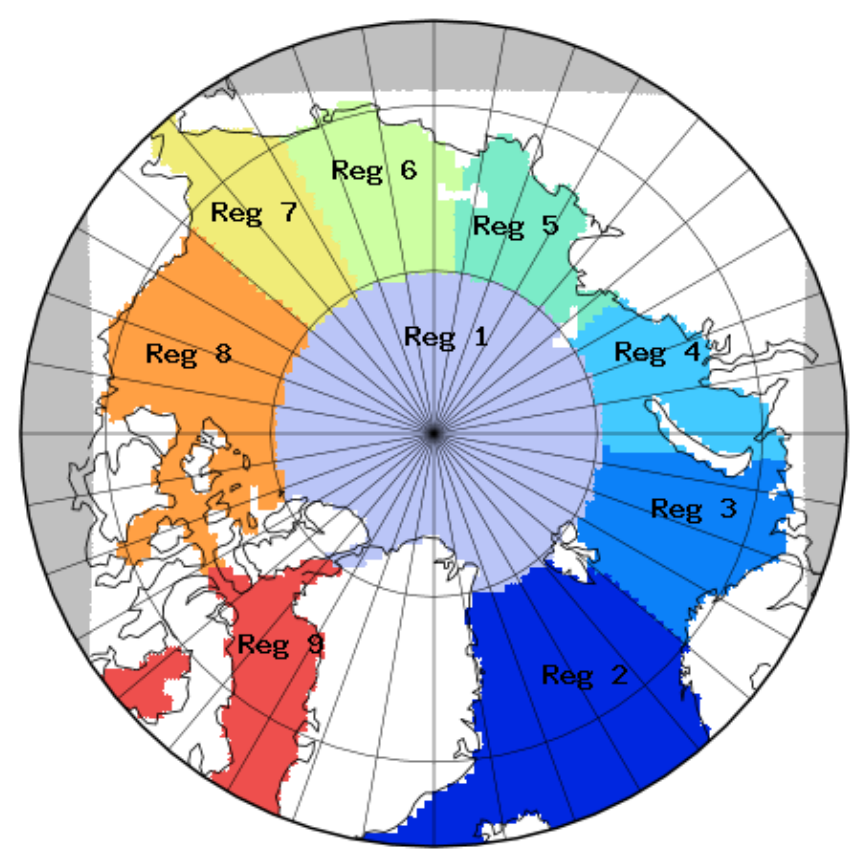

Figure 2. Sub-regions defined in the study. 1 (light plum): central Arctic. 2 (dark blue): North Atlantic; and then counterclockwise to 7 (yellow): Bering Strait/Chukchi Sea; 8 (orange): Beaufort Sea; 9 (red): Baffin Bay.

quantity. In other words, it does not help to constrain parts of the control space that have no impact on the target quantity (as quantified by $N^{\prime}$ ). Specific examples and further discussion of how to interpret the matrix $N^{\prime}$ will be provided in Sect. 4 below.

We note that (through Eqs. 3 and 4) the posterior target uncertainty solely depends on the prior and data uncertainties as well as the linearised model responses of simulated observation counterparts and of target quantities. The approach does not require real observations and can thus be employed to evaluate hypothetical candidate networks. Candidate networks are defined by a set of observations characterised by observational data type, location, time, and data uncertainty. Hence, the QND approach does not require running the assimilation system. Here, we define a network as the complete set of observations, $d$, used to constrain the model. The term network is not meant to imply that the observations are of the same type or that their sampling is coordinated. For example, a network can combine in situ and satellite observations.

In practice, for pre-defined target quantities and observations, model responses can be pre-computed and stored. A network composed of these pre-defined observations can then be evaluated in terms of the pre-defined target quantities without further model evaluation. Only matrix algebra is required to combine the pre-computed sensitivities with the data uncertainties. This aspect is exploited in our AOND system. The linearised response functions were computed by the tangent linear version of NAOSIM generated from the model's source code through the automatic differentiation tool Transformation of Algorithms in Fortran (TAF; Giering and Kaminski, 1998).

\section{Experimental setup}

\subsection{Target quantities}

The goal of this study is to explore the utility of the AOND system in guiding observations for short-term to seasonalscale sea ice predictions. Ice forecasting at these timescales has been identified as a high priority in the context of safe maritime operations (Richter-Menge and Walsh, 2012; Kurtz et al., 2013a; Eicken, 2013), management of marine living resources (Robards et al., 2013) and food security for indigenous communities (Brubaker et al., 2011). Here, we focus on the first two issues in the Chukchi and Beaufort seas north of Alaska (Figs. 1 and 2), which are experiencing some of the highest reductions in summer ice concentration anywhere in the Arctic, along with major offshore hydrocarbon exploration and potential impacts on protected species such as walrus (Eicken and Mahoney, 2015). Thus, the selection of target quantities for the AOND system seeks to evaluate and improve predictions aimed at the information needs of stakeholders and resource managers for this region. Of particular interest is the summer season with its reduced ice cover. From an observational point of view this period is particularly challenging, as surface melt and its impact on ice dielectric properties complicate retrievals of variables such as snow depth and ice thickness through satellite remote sensing. For this study we deliberately selected the year 2007, a year of particularly low ice extent, which may be regarded as representative of future ice conditions in a rapidly changing Arctic. As is detailed in the following, we study both predictions for selected days and predictions for integrals over selected time periods.

For all target regions delineated in Fig. 1, we use spatial averages of the three simulated quantities: ice concentration (fraction of area covered by ice, regardless of the $15 \%$ floor used in the definition of ice extent), ice thickness, and snow thickness. For each of the target regions we look at these quantities for different days or time periods. For the target region Chukchi Sea we examine these three quantities for each of 10 April, 30 June, and 31 August, yielding a total of nine target quantities. In order to specifically address information needs with respect to safe shipping between Bering Strait and the central and eastern Beaufort Sea (including supply of coastal communities and the oil industry hub at Prudhoe Bay, offshore resource exploration and transits through the Northwest Passage), we evaluate an additional set of target quantities derived from the Barnett ice severity index (BSI). The BSI has developed into a standard measure of shipping conditions and potential hazards encountered along the Alaskan coast and at a critical choke point of the Northwest Passage, 
and it is routinely issued by ice services (Barnett, 1976). Drobot (2003) has examined the predictive skill of statistical models in BSI seasonal forecasts. The BSI is a composite of eight aspects of summer ice conditions (see Table 2), four related to the distance of the ice pack north of Point Barrow (NOB) in mid-August and mid-September and four related to the timing of ice retreat along the sea route from Bering Strait to Prudhoe Bay during the entire navigation season (BS2PB). In replicating these variables in a condensed way, we identify the two target regions as shown in Fig. 1. The target region NOB covers a corridor of $50 \mathrm{~km}$ (one grid cell) width extending from Point Barrow to $75^{\circ} \mathrm{N}$ on 10 and 31 August. We use 31 August in contrast to 15 September (which is used in the definition of the BSI) because from the end of August to mid-September 2007 the ice edge was located northwards of $75^{\circ} \mathrm{N}$. For the region BS2PB, in keeping with the BSI we use the time period from May to August.

\subsection{Control variables}

In our variational assimilation system the largest possible control vector is the superset of initial and surface boundary conditions as well as all parameters in the process formulations. To keep our AOND system numerically efficient, twoand three-dimensional fields are grouped into regions. We proceeded by dividing the Arctic domain into nine regions (Fig. 2). In each of these regions we add a scalar perturbation to each of the forcing fields (indicated in Table 1 by the type boundary " $f$ "). Likewise we add a scalar perturbation to five initial fields (indicated in Table 1 by the type initial " $i$ "). For the ocean temperature and salinity the size of the perturbation is reduced with increasing depth. Finally we have selected 18 process parameters from the sea ice-ocean model. This procedure resulted in a total of 126 control variables, a superset of the set of control variables identified by Sumata et al. (2013) to have the largest impact on the simulation. Unlike the study by Kauker et al. (2009) the control vector used here also includes process parameters. We conducted sensitivity experiments in which we remove components from the control vector. For example, removing the atmospheric forcing explores the (hypothetical) case of a perfect seasonal atmospheric forecast, and removing the process parameters the (hypothetical) case of a perfectly calibrated model.

The prior uncertainty of the control variables, $\mathbf{C}\left(x_{0}\right)$ (see Eqs. 1 and 3), is assumed to have diagonal form; i.e. there are no correlations among the prior uncertainty relating to different components of the control vector. The diagonal entries are the square of the prior uncertainty (quantified by its standard deviation, in the following denoted as SD or prior sigma). For process parameters this SD is estimated from the range of values typically used within the modelling community. The SD for the components of the initial state is based on a model simulation over the past 20 years and computed for the 20-member ensemble corresponding to all states on the same day of the year. Likewise the SD for the surface boundary conditions is computed for the 20-member ensemble corresponding to all 5-month forecast periods starting on the same day of the year.

As the QND approach does not require the minimisation of Eq. (1), the prior uncertainty only serves as a reference such that the impact of observations is quantified in terms of a percentage change relative to the prior uncertainty (uncertainty reduction). If the prior uncertainty were too optimistic, the impact of the observations would be underestimated, and vice versa: if the prior uncertainty were too high, the impact of the observations would be overestimated. As we will use the same prior uncertainty as the reference for all observational configurations, their relative performance is not affected.

\subsection{Observational networks}

There are various types of observations sampling the Arctic sea ice-ocean system, many of which are potentially suitable for assimilation into a model like NAOSIMDAS. Our AOND system focuses on observations of ice concentration (not used in the present study), snow depth and ice thickness. It provides response functions for potential observations of each of these three observables, for each surface grid cell, and for each day of the simulation period (i.e. about 5 million possible observations of which subsets can be selected for evaluation) with a user-defined data uncertainty. In this study we demonstrate the application and potential utility of the system in evaluating the relative merits and quantitative contribution to improving sea ice forecasts for two alternate ice thickness airborne survey profiles. This example is based on the need for objective guidance on flight routing as part of NASA's Operation IceBridge, an airborne laser altimeter and snow radar campaign meant to provide information on the mass budget of the Arctic ice pack (Richter-Menge and Farrell, 2013). Recent work has demonstrated the utility of such data, collected in spring for initialisation and constraints on seasonal forecasts of summer ice extent (Lindsay et al., 2012; Kurtz et al., 2013a). Based on an evaluation of flown and hypothetical IceBridge transects, we evaluate the impact of simulated measurements along two transects within AOND. The first is a transect from Bering Strait to Fram Strait, which we denote by Chukchi to Fram (C2F, Fig. 1, red), and the second from the Beaufort Sea to Fram Strait, which we denote by Beaufort to Fram (B2F, Fig. 1, yellow). Both flights are assumed to take place on 5 April 2007. The "observations" consist of model output of ice and snow thickness at each grid cell that intersects with the transect as indicated in Fig. 1. The default case specifies a data uncertainty of $30 \mathrm{~cm}$ for both quantities. Sea ice concentration is not observed. To explore the sensitivity of the results with respect to the data uncertainty, we also test a data uncertainty of $10 \mathrm{~cm}$. While the former is at the lower end of what is expected for IceBridge altimeter data (Kurtz et al., 2013b), the latter corresponds to 
Table 2. Aspects entering the definition of the Barnett ice severity index.

Distance from Point Barrow northward to ice edge (10 Aug).

Distance from Point Barrow northward to ice edge (15 Sep).

Distance from Point Barrow northward to boundary of 5/10 ice concentration (10 Aug).

Distance from Point Barrow northward to boundary of 5/10 ice concentration (15 Sep).

Initial date entire sea route to Prudhoe Bay less than/equal to 5/10 ice concentration.

Date that combined ice concentration and thickness dictate end of prudent navigation.

Number of days entire sea route to Prudhoe Bay ice-free.

Number of days entire sea route to Prudhoe Bay less than/equal to 5/10 ice concentration.

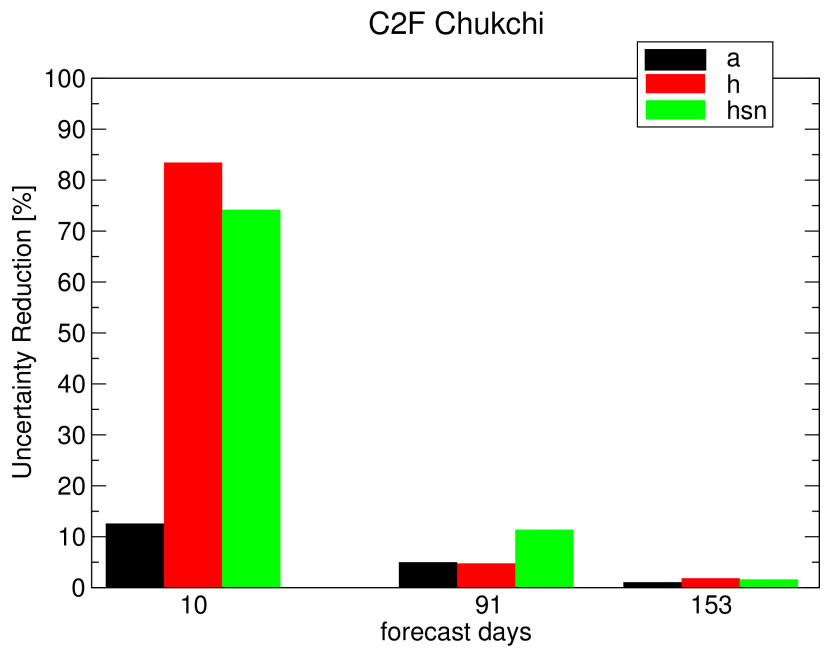

(a)

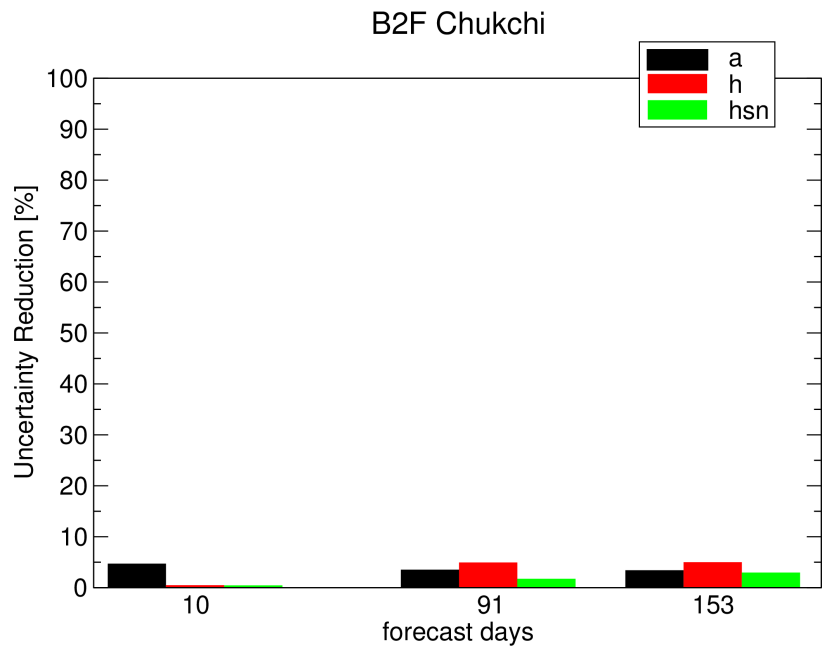

(b)

Figure 3. Uncertainty reduction for the Chukchi target area for flight transect C2F (a) and B2F (b) for target quantities mean ice concentration $a$, mean ice thickness $h$ and mean snow depth $h s n$.

the lower bounds of airborne electromagnetic induction measurements (Haas et al., 2009).

\section{Results and discussion}

Figure 3 shows the performance of each transect in improving forecasts over the Chukchi target region. We define the uncertainty reduction relative to the case without observational constraints, where the prior uncertainty in the control vector (see Sect. 3.2) is propagated to the three target quantities. Overall we note a larger impact of $\mathrm{C} 2 \mathrm{~F}$ on the shortterm forecast (10 days), while for B2F the impact increases for the mid-term forecast (3 months). For the mid-term forecast $\mathrm{C} 2 \mathrm{~F}$ surpasses $\mathrm{B} 2 \mathrm{~F}$ with respect to the impact on predicted ice concentration and snow thickness, while its impact is marginally smaller for ice thickness. For the 10 day forecast $\mathrm{C} 2 \mathrm{~F}$ has a much larger impact on predicted ice and snow thickness than on ice concentration. This is mostly a result of the flights observing specifically the former two quantities, whereas the model dynamics require some time to transfer any constraints on snow and ice thickness into constraints on ice concentration. Moreover, ice concentration in this re- gion is also strongly dependent on factors other than snow and ice thickness, in particular during spring and early summer, when the role of wind forcing greatly exceeds that of the other two variables.

Mathematically, through $N^{\prime}$ in Eq. (4), each target quantity defines a one-dimensional sub-space (target direction; Kaminski et al., 2012) of the space spanned by the control vector (control space). All control vectors $v$ perpendicular to the target direction yield $N^{\prime} v=0$. Similarly, through $M^{\prime}$ in Eq. (3) each observation defines a second one-dimensional sub-space of the control space, the observed direction. The better the observed direction projects onto the target direction, the more efficient is the observation in reducing the uncertainty in the target quantity. According to Eq. (3) the uncertainty reduction increases with the response of the observable to a change in the control vector $\left(M^{\prime}\right)$ and decreases with the data uncertainty. Figure 4 provides a visualisation of the complete matrix $N^{\prime}$, which shows the response of the three target quantities to a change in each of the control variables by $1 \mathrm{SD}$ of the prior probability density function (Table 1 ). The position on the $x$ axis corresponds to the number of the control variable in the last column of Table 1 . This provides 


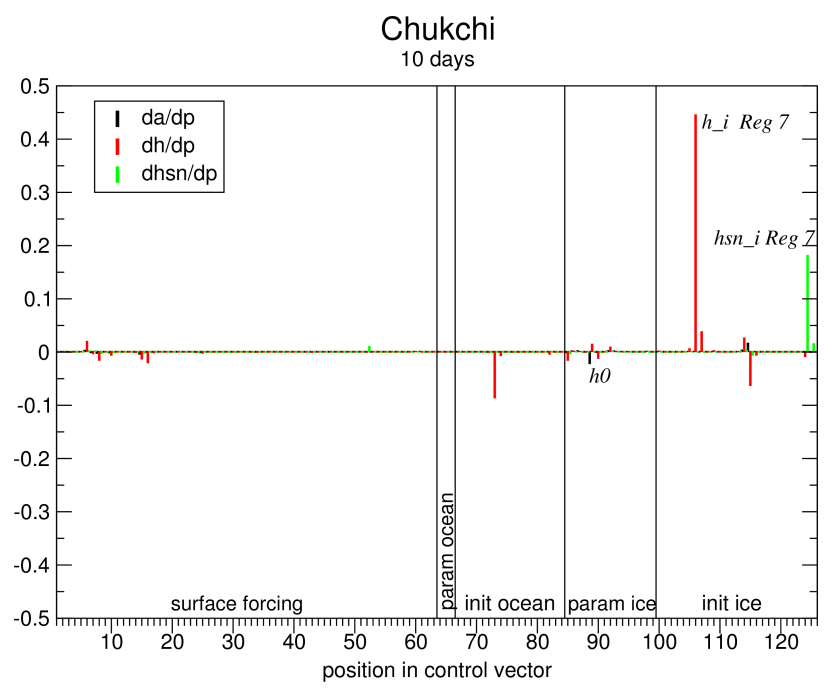

(a)

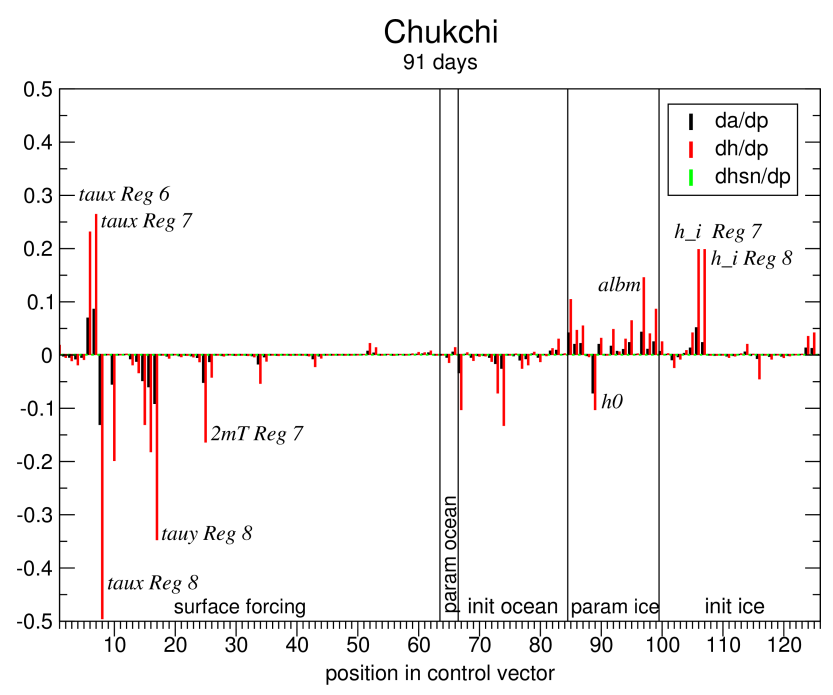

(b)

Figure 4. Sensitivity of target quantities over Chukchi area for 10-day (a) and 91-day (b) forecasts to 1 prior sigma uncertainty change in each control variable. Units of target quantities (and their sensitivities): ice concentration $(a)(0-1)$; ice thickness $(h)$ in metres; snow thickness $(h s n)$ in metres.

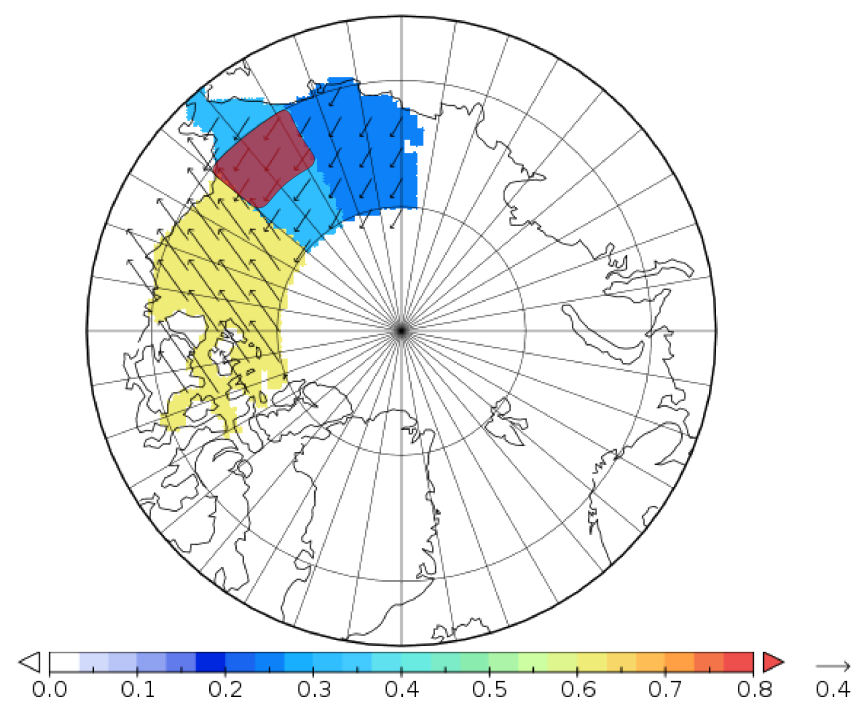

Figure 5. Wind stress direction with highest impact of tau component in control vector on ice thickness in Chukchi target region (dark red colour). Colour indicates magnitude.

two pieces of information: first, it shows the target direction; second, it shows the size of the impact of an uncertainty reduction in the target direction. We note that the initial conditions of ice and snow have highest impact for the short-term forecast. For the mid-term forecast, atmospheric forcing and model parameters gain in importance. For the interpretation of the wind stress components taux and tauy recall that the model operates on a rotated coordinate system. Taking the rotation into account, for regions 6,7 , and 8 Fig. 5 shows the direction in which a change of tau yields the largest increase in ice thickness. Adding a $25^{\circ}$ Ekman deflection, the change of ice motion is towards the target region. For the long-term forecast (153 days), the impacts (not shown) are generally small because there is little ice left in the target area. The impact of the B2F transect on the 10-day forecast of ice concentration over the (remote) Chukchi target region (Fig. 3b) is remarkable. It is explained by the relatively high impact of the lead closing parameter $h_{0}$ in the formulation of freezing (control variable \#89) on ice concentration (Fig. 4). Since $h_{0}$ is a global parameter, observations on both transects can help to reduce uncertainty in this parameter.

Figure 6 shows the performance of each transect for improving forecasts for the target region covering the coastal ocean from Bering Strait to Prudhoe Bay (BS2PB). They show similar performance because this target quantity is temporally averaged from May to August. B2F is superior for snow thickness, and $\mathrm{C} 2 \mathrm{~F}$ for ice thickness and area. This can be explained by the sensitivity of these three target quantities (Fig. 7). Relative to ice thickness and area, snow thickness has a larger sensitivity to the initial (ice and snow) conditions (in particular over region 8) than to the surface forcing and the process parameters. And the initial snow thickness over region 8 is, of course, better observed by B2F (which crosses this region) than by $\mathrm{C} 2 \mathrm{~F}$. As an additional test case we evaluate the combination of the two transects, which clearly shows their complementarity.

Figure 7 shows the response of the three target quantities to a 1 prior sigma change in each of the control variables. The impact of wind stress dominates. For both region 7 and 8 , Fig. 8 shows the direction in which a change of tau yields 


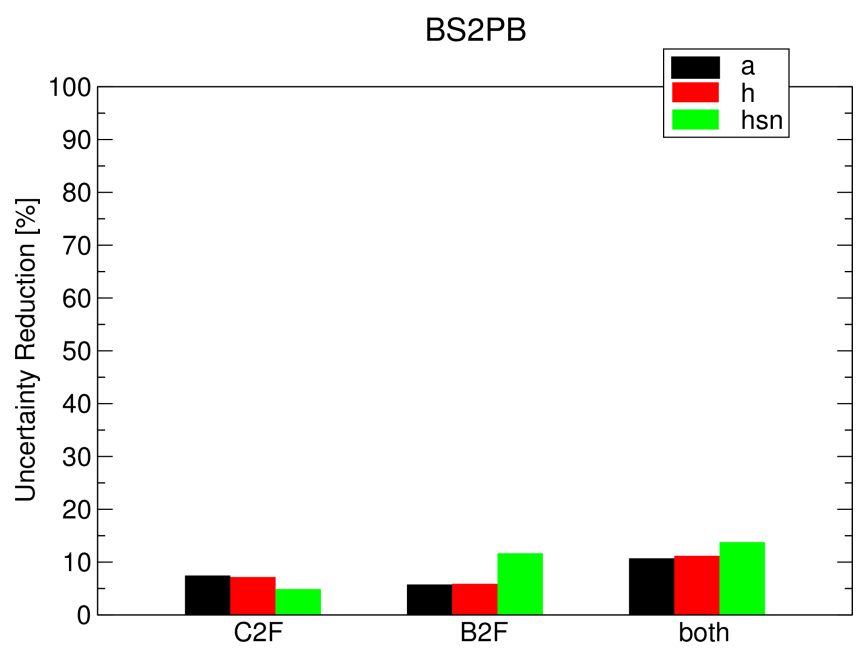

Figure 6. Uncertainty reduction for target area BS2PB for flight transects $\mathrm{C} 2 \mathrm{~F}, \mathrm{~B} 2 \mathrm{~F}$, and both.

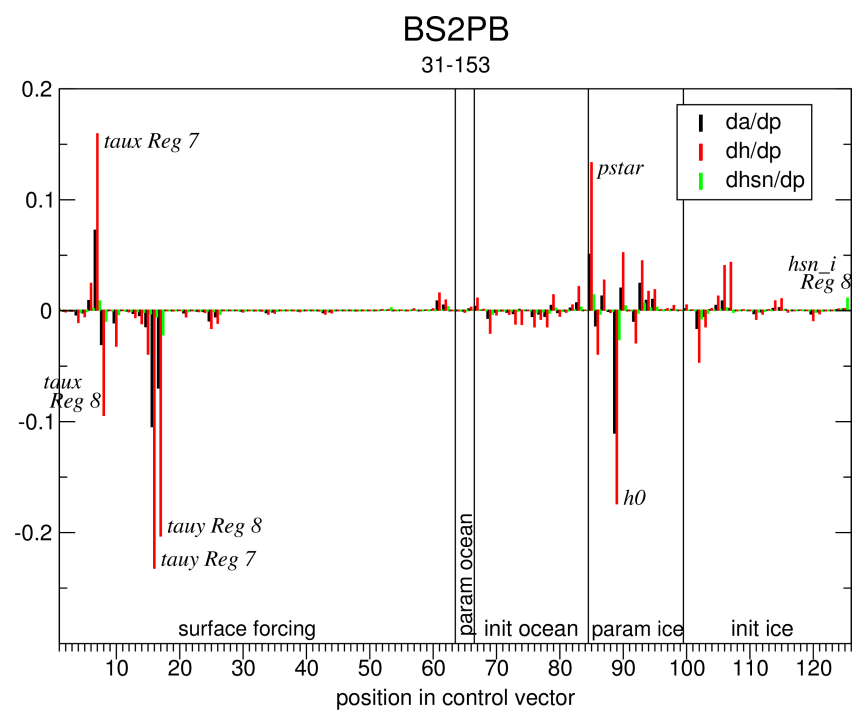

Figure 7. Sensitivity of target quantities for BS2PB area to 1 prior sigma uncertainty change in each control variable. Units of target quantities (and their sensitivities): ice concentration $(a)(0-1)$; ice thickness $(h)$ in metres; snow thickness $(h s n)$ in metres.

the largest increase in ice thickness. Adding a $25^{\circ}$ Ekman deflection (to the right) the change of ice motion is towards the intersection of the respective region's coastline with the target area BS2PB. The parameter pstar has a positive impact because it yields more rigid ice. Parameter $h_{0}$, which essentially determines the distribution of newly formed ice in the vertical vs. the horizontal dimension, has a negative impact: increasing $h_{0}$ yields thicker newly formed ice and consequently reduces the ice concentration.

Figure 9 shows the performance of each transect for improving forecasts over the NOB target region. The performance of $\mathrm{B} 2 \mathrm{~F}$ is much better than that of $\mathrm{C} 2 \mathrm{~F}$ for both fore-

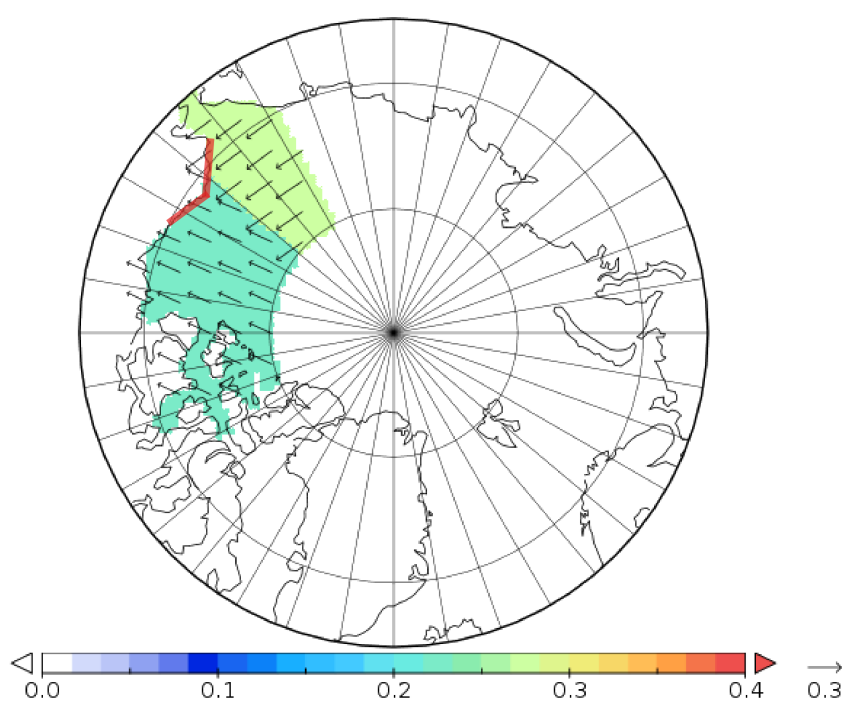

Figure 8. Wind stress direction with highest impact of tau component in control vector on ice thickness in BS2PB target region (dark red colour). Colour indicates magnitude.

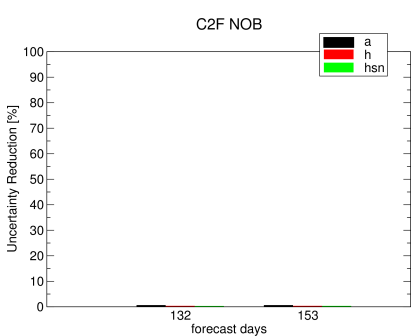

(a)

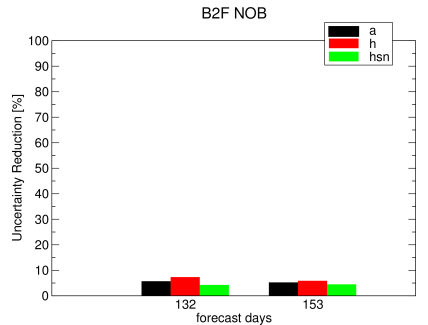

(b)
Figure 9. Uncertainty reduction for target areas NOB for flight transect C2F (panel a) and B2F (panel b).

cast times. This result appears counter-intuitive, because $\mathrm{C} 2 \mathrm{~F}$ is much closer than B2F, but can be explained through the influence of the westward circulation prevailing in the waters off the Alaskan coast (Eicken and Mahoney, 2015). For forecast times of 4-5 months, an upstream observation is associated with much more predictive skill than an observation directly over the target area. In fact the same mechanism explains the previously mentioned higher uncertainty reduction of B2F for the long-term forecast in the Chukchi area. For the target area BS2PB none of the transects dominate because the target period is an integral from forecast months 2 to 5 .

Figure 10 shows the response of the three target quantities (on both 10 and 31 August) to a 1 prior sigma change in each of the control variables. We note the highest impact for tauy in region 8 (positive impact of southwest increase), leading to more ice in the target region (see Fig. 11). Furthermore there is relatively high impact of other atmospheric forcing variables, as well as of some parameters (the albedo of melt- 


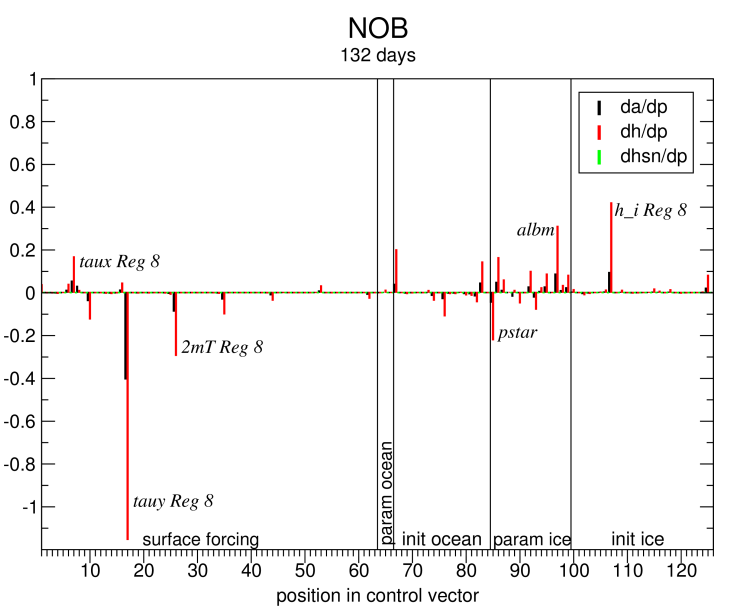

(a)

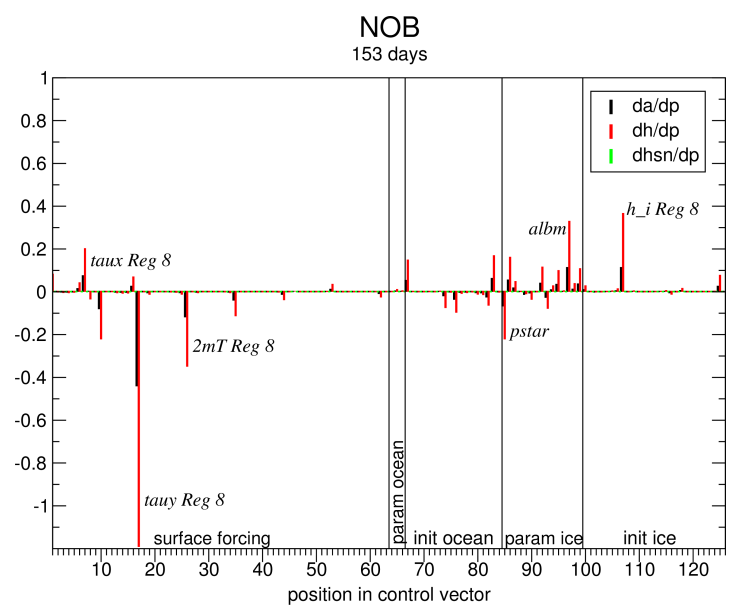

(b)

Figure 10. Sensitivity of target quantity over NOB area for 132-day (a) and 153-day (b) forecasts to 1 prior sigma uncertainty change in each control variable. Units of target quantities (and their sensitivities): ice concentration $(a)(0-1)$; ice thickness $(h)$ in metres; snow thickness ( hsn) in metres.

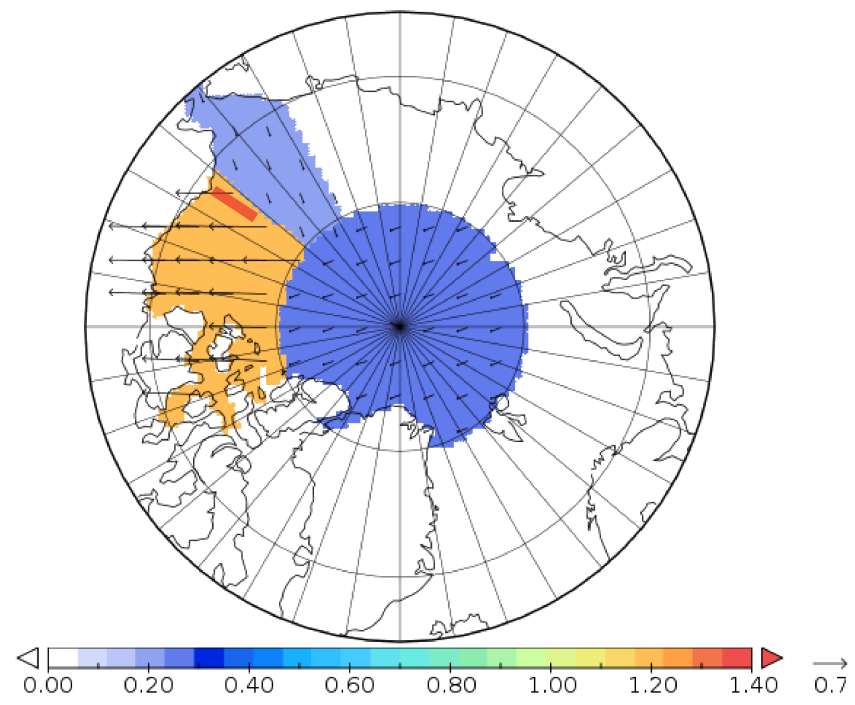

Figure 11. Wind stress direction with highest impact of tau component in control vector on ice thickness in NOB target region (dark red colour). Colour indicates magnitude.

ing ice, albm, and the ice strength parameter, pstar) and the ice initial conditions.

There is generally little difference in the responses for the two forecast periods. This is an indication of the robustness of our linearisation of the coupled sea ice-ocean system and confirms an analysis of Kauker et al. (2009), who found, for the same model, moderate differences between the linearisation and finite size perturbations. A consequence of this robustness is that the specific target days we chose only play the role of a typical day within a longer time period.
Figure 12 shows the sensitivity of the performance of the (superior) B2F transect with respect to changes in various impact factors (relative to the default settings used for Fig. 9) for the NOB target region. The reduction in data uncertainty from 0.3 to $0.1 \mathrm{~m}$ for both ice and snow thickness yields a considerable improvement in performance (panel a). The effect is particularly pronounced for ice area. Reducing the prior uncertainty for the atmospheric forcing to zero mimics the availability of a perfect seasonal atmospheric forecast. Under this assumption, the performance of the B2F transect is strongly increased (panel b). Likewise a reduction of the prior uncertainty for all process parameters mimics a perfectly calibrated model. Its effect on the performance of the $\mathrm{B} 2 \mathrm{~F}$ transect is relatively small (panel c). Interestingly, combining the perfectly calibrated model and the perfect atmospheric forecast assumptions doubles the uncertainty reductions compared to the perfect atmospheric forecast assumptions alone. In this case all the observational constraints can fully act to reduce uncertainty in the initial conditions.

\section{Conclusions}

We have presented the AOND system that evaluates hypothetical observational networks of the coupled sea ice-ocean system in terms of their constraint on target quantities of interest within an assimilation system. We have applied the tool to evaluate the potential of two flight transects to reduce uncertainties in ice forecasts over periods from 10 days to 5 months for regions with high offshore resource exploration (Chukchi Sea) or shipping activity (Northwest Passage). For our analysis and case study we selected the year 2007, a year of particularly low ice extent, which may be regarded as rep- 


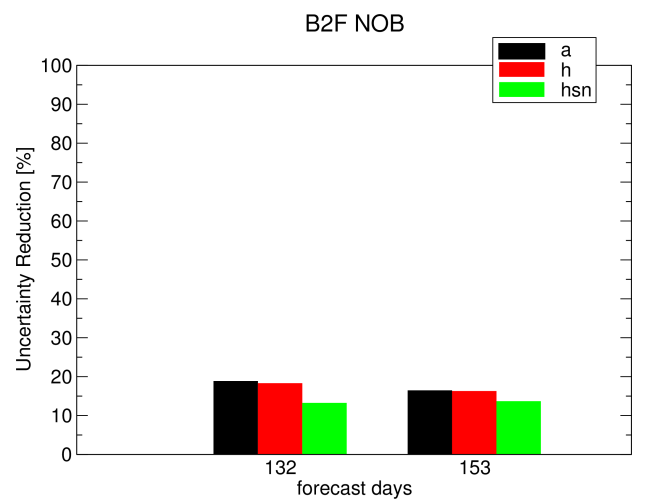

(a) Reduced Data Uncertainty

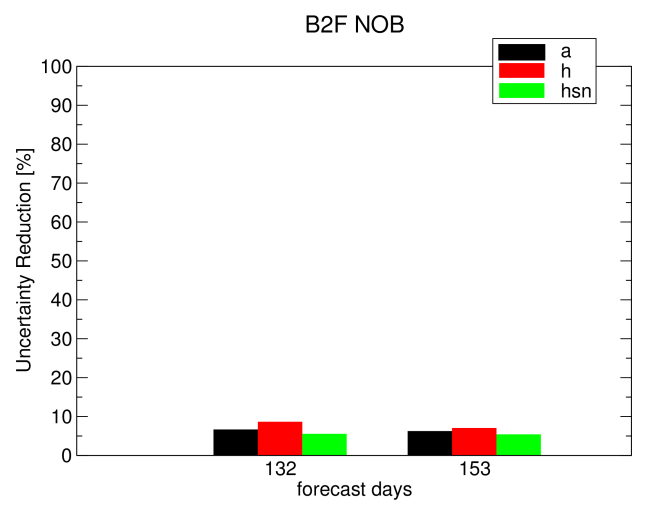

(c) Perfect Model

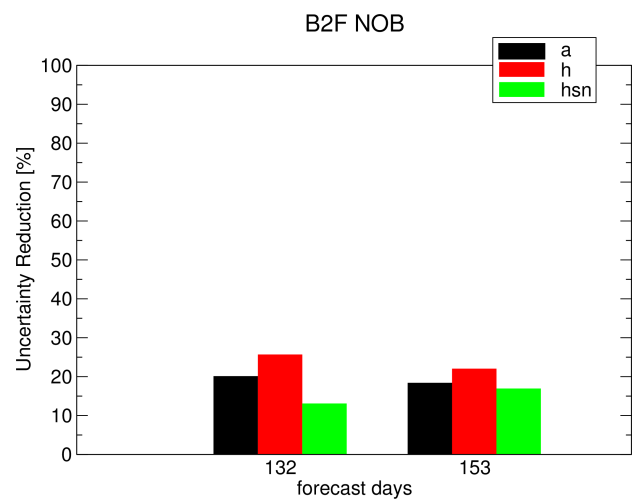

(b) Perfect Forcing

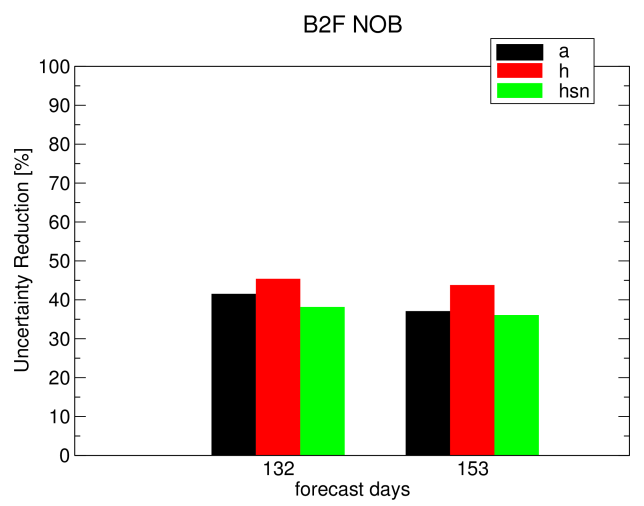

(d) Perfect Model and Forcing

Figure 12. Uncertainty reduction for target areas NOB for flight transect B2F with data uncertainty of $0.1 \mathrm{~m}$ (a), the assumption of perfectly known atmospheric forcing (b), the assumption of a perfectly calibrated model (c), the assumption of perfectly known atmospheric forcing and of a perfectly calibrated model $(\mathbf{d})$.

resentative of future ice conditions in a rapidly changing Arctic.

Since our quantitative results are specific to the conditions in this particular year, we focus on overarching conclusions that can be drawn from this case study. First, we note that the network performance depends on the specific question asked, i.e. on the target quantity. Of equal importance in the highly advective Arctic sea ice regime is the finding that the longer the forecast time, the further upstream we have to sample, well outside of the region of interest. This may result in significant interannual variability in the area that needs to be targeted for measurements relative to the region of interest. This finding also supports the broader notion of an adaptive sampling grid that reflects a priori knowledge of the state and dynamics of the ice cover at the end of the ice growth season. On another level, we furthermore demonstrated in a quantitative way how the model dynamics transfer the observational information from one set of variables (snow depth and ice thickness) to another variable (ice concentration). In this context, we note that in our case study the target quantities and framework for assessing the QND were based on the specific objective of predicting summer ice conditions or navigation along a heavily trafficked route in the Alaskan Arctic at the seasonal scale. Future work will have to evaluate the degree of overlap in uncertainty reduction for predictions on seasonal as compared to interannual or multidecadal timescales.

When defining candidate networks to be evaluated, it is essential to take logistic constraints into account. The selection of alternate flight routes for the $\mathrm{C} 2 \mathrm{~F}$ and $\mathrm{B} 2 \mathrm{~F}$ transects inherently reflects logistic factors. However, the QND approach lends itself to inclusion of quantitative constraints on specific regional data acquisition patterns that may require further work to evaluate. Similarly, an essential input to the tool is the data uncertainty, which is the combination of uncertainties in the observations and in modelling their counterparts (model uncertainty). Hence, the QND approach can also help in evaluating methodological improvements or evaluate the costs/benefits of advances in instrumental design that reduce measurement errors. These findings make it clear that a QND tool needs to be operated by a team consisting of observationalists and modellers in order to derive maximum benefits.

We note that the aforementioned model uncertainty to be provided to the tool does not necessarily need to refer to the 
specific model that is used. As long as the response functions of our model are approximately correct, we can use the present system to simulate the observational impact on an assimilation system around a different model. For QND results to be valid beyond the model at hand, one has to employ a well-validated model that includes all relevant processes. For example the model should have adequate sensitivity of regionally integrated ice properties with respect to the initial ice thickness. For the model used here this sensitivity is similar for resolutions from $1 / 2$ to $1 / 12$ of a degree. One would not expect a drastic change of this sensitivity when moving to even finer (eddy-permitting) scales, but this requires further investigation. Computationally, the current 126-dimension control space requires 127 model simulations (over 5 months each) for the approximation of the Jacobian matrices ( $M^{\prime}$ of Eq. 3 and $N^{\prime}$ of Eq. 4) quantifying observational and target sensitivities. This should be feasible even for high-resolution models.

The current AOND system has the flexibility to also evaluate the potential of space missions or further in situ sampling strategies. There are a number of obvious ways to refine the present system. It can be extended to cover climate conditions over longer timescales and further into the future, possibly also representative of the state of the Arctic under climate change scenario for mid-century and beyond. Moreover, one could add oceanic observations or further target quantities, or extend the control vector to gain broader insights into observing system design in the coupled atmosphere-sea ice-ocean system. Furthermore, rather than operating Arctic-wide, the same concept can be applied on a smaller regional scale when the forecasting period is short enough to ensure that the main influence factors can be appropriately simulated within the model domain.

Acknowledgements. This work has been funded by the European Commission through its Seventh Framework Programme Research and Technological Development under contract number 265863 (ACCESS) through a grant to FastOpt and OASys and by the National Science Foundation as part of the Sea Ice Prediction Network (SIPN) under grant number PLR-1304315. The authors thank two anonymous reviewers and Christian Haas for valuable comments on the manuscript.

Edited by: C. Haas

\section{References}

Barnett, D. G.: A practical method of long-range ice forecasting for the north coast of Alaska, Part I, Technical Report TR-1, Fleet Weather Facility, Suitland, Maryland, 1976.

Brubaker, M., Berner, J., Chavan, R., and Warren, J.: Climate change and health effects in Northwest Alaska, Glob. Health Action, 4, 8445, doi:10.3402/gha.v4i0.8445 2011.

Castro-Morales, K., Kauker, F., Losch, M., Hendricks, S., RiemannCampe, K., and Gerdes, R.: Sensitivity of simulated Arctic sea ice to realistic ice thickness distributions and snow parameterizations, J. Geophys. Res., 119, 559-571, 2014.

Crisp, D., Atlas, R., Breon, F.-M., Brown, L., Burrows, J., Ciais, P., Connor, B., Doney, S., Fung, I., Jacob, D., Miller, C., O'Brien, D., Pawson, S., Randerson, J., Rayner, P., Salawitch, R., Sander, S., Sen, B., Stephens, G., Tans, P., Toon, G., Wennberg, P., Wofsy, S., Yung, Y., Kuang, Z., Chudasama, B., Sprague, G., Weiss, B., Pollock, R., Kenyon, D., and Schroll, S.: The Orbiting Carbon Observatory (OCO) mission. Trace constituents in the troposphere and lower stratosphere, Adv. Space Res., 34, 700-709, 2004.

Drobot, S.: Long-range statistical forecasting of ice severity in the Beaufort-Chukchi Sea, Weather Forecast., 18, 1161-1176, 2003.

Eicken, H.: Arctic sea ice needs better forecasts, Nature, 497, 431433, 2013.

Eicken, H. and Mahoney, A. R.: Sea ice: hazards, risks and implications for disasters, in: Coastal and Marine Hazards, Risks, and Disasters, edited by: Ellis, J. and Sherman, D., Elsevier, Oxford, 381-401, 2015.

Giering, R. and Kaminski, T.: Recipes for adjoint code construction, ACM T. Math. Software, 24, 437-474, 1998.

Haas, C., Lobach, J., Hendricks, S., Rabenstein, L., and Pfaffling, A.: Helicopter-borne measurements of sea ice thickness, using a small and lightweight, digital EM system, J. Appl. Geophys., 67, 234-241, 2009.

Hardt, M. and Scherbaum, F.: The design of optimum networks for aftershock recordings, Geophys. J. Int., 117, 716-726, 1994.

Hibler, W.: A dynamic thermodynamic sea ice model, J. Geophys. Res., 9, 815-846, 1979.

Hibler, W. I. and Bryan, K.: A diagnostic ice-ocean model, J. Phys. Oceanogr., 17, 987-1015, 1987.

Kadygrov, N., Maksyutov, S., Eguchi, N., Aoki, T., Nakazawa, T., Yokota, T., and Inoue, G.: Role of simulated GOSAT total column $\mathrm{CO}_{2}$ observations in surface $\mathrm{CO}_{2}$ flux uncertainty reduction, J. Geophys. Res.-Atmos., 114, D21208, doi:10.1029/2008JD011597, 2009.

Kalnay, E., Kanamitsu, M., Kistler, R., Collins, W., Deaven, D., Gandin, L., Iredell, M., Saha, S., White, G., Woollen, J., Zhu, Y., Chelliah, M., Ebisuzaki, W., Higgins, W., Janowiak, J., Mo, K. C., Ropelewski, C., Wang, J., Leetmaa, A., Reynolds, R., Jenne, R., and Joseph, D.: The NCEP/NCAR 40-year reanalysis project, B. Am. Meteorol. Soc., 77, 437-471, 1996.

Kaminski, T. and Rayner, P. J.: Assimilation and network design, in: Observing the Continental Scale Greenhouse Gas Balance of Europe, edited by: Dolman, H., Freibauer, A., and Valentini, R., Ecological Studies, chap. 3, Springer-Verlag, New York, 2008.

Kaminski, T., Scholze, M., and Houweling, S.: Quantifying the benefit of A-SCOPE data for reducing uncertainties in terrestrial carbon fluxes in CCDAS, Tellus B, 62, 784-796, 2010.

Kaminski, T., Rayner, P. J., Voßbeck, M., Scholze, M., and Koffi, E.: Observing the continental-scale carbon balance: assessment of sampling complementarity and redundancy in a terrestrial assimilation system by means of quantitative network design, Atmos. Chem. Phys., 12, 7867-7879, doi:10.5194/acp-12-78672012, 2012.

Kauker, F., Gerdes, R., Karcher, M., Köberle, C., and Lieser, J.: Variability of Arctic and North Atlantic sea ice: a combined analysis of model results and observations from 1978 to 2001, J. Geo- 
phys. Res.-Oceans, 108, C63182, doi:10.1029/2002JC001573, 2003.

Kauker, F., Kaminski, T., Karcher, M., Giering, R., Gerdes, R., and Voßbeck, M.: Adjoint analysis of the 2007 all time Arctic sea-ice minimum, Geophys. Res. Lett.,, 36, L03707, doi:10.1029/2008GL036323, 2009.

Kauker, F., Gerdes, R., Karcher, M., Kaminski, T., Giering, R., and Voßbeck, M.: June 2010 Sea Ice Outlook - AWI/FastOpt/OASys, Sea Ice Outlook web page, available at: http://www.arcus.org/ search/seaiceoutlook/index.php (last access: 17 March 2015), 2010.

Köberle, C. and Gerdes, R.: Mechanisms determining the variability 2003: mechanisms determining the variability of Arctic sea ice conditions and export, J. Climate, 16, 2843-2858, 2003.

Kurtz, N. T., Richter-Menge, J., Farrell, S., Studinger, M., Paden, J., Sonntag, J., and Yungel, J.: IceBridge Airborne Survey Data Support Arctic Sea Ice Predictions, EOS T. Am. Geophys. Un., 94, p. 41, doi:10.1002/2013eo040001, 2013a.

Kurtz, N. T., Farrell, S. L., Studinger, M., Galin, N., Harbeck, J. P., Lindsay, R., Onana, V. D., Panzer, B., and Sonntag, J. G.: Sea ice thickness, freeboard, and snow depth products from Operation IceBridge airborne data, The Cryosphere, 7, 1035-1056, doi:10.5194/tc-7-1035-2013, 2013b.

Lindsay, R., Haas, C., Hendricks, S., Hunkeler, P., Kurtz, N., Paden, J., Panzer, B., Sonntag, J., Yungel, J., and Zhang, J.: Seasonal forecasts of Arctic sea ice initialized with observations of ice thickness, Geophys. Res. Lett., 39, L21502, doi:10.1029/2012GL053576, 2012.

Nickless, A., Ziehn, T., Rayner, P.J., Scholes, R.J., and Engelbrecht, F.: Greenhouse gas network design using backward Lagrangian particle dispersion modelling - Part 2: Sensitivity analyses and South African test case, Atmos. Chem. Phys., 15, 20512069, doi:10.5194/acp-15-2051-2015, 2015.

O'Brien, D. M. and Rayner, P. J.: Global observations of the carbon budget, 2, $\mathrm{CO}_{2}$ column from differential absorption of reflected sunlight in the $1.61 \mu \mathrm{m}$ band of $\mathrm{CO}_{2}$, J. Geophys. Res.-Atmos., 107, ACH 6-1-ACH 6-16, doi:10.1029/2001JD000617, 2002.

Parkinson, C. and Washington, W.: A large-scale numerical model of sea ice, J. Geophys. Res., 84, 311-337, 1979.

Patra, P. K., Maksyutov, S., Sasano, Y., Nakajima, H., Inoue, G., and Nakazawa, T.: An evaluation of $\mathrm{CO}_{2}$ observations with Solar occultation FTS for inclined-orbit satellite sensor for surface source inversion, J. Geophys. Res.-Atmos., 108, 4759, doi:10.1029/2003JD003661, 2003.
Rayner, P. J. and O'Brien, D. M.: The utility of remotely sensed $\mathrm{CO}_{2}$ concentration data in surface source inversions, Geophys. Res. Lett., 28, 175-178, 2001.

Rayner, P. J., Enting, I. G., and Trudinger, C. M.: Optimizing the $\mathrm{CO}_{2}$ observing network for constraining sources and sinks, Tellus B, 48, 433-444, 1996.

Rayner, P. J., Law, R. M., O'Brien, D. M., Butler, T. M., and Dilley, A. C.: Global observations of the carbon budget 3. Initial assessment of the impact of satellite orbit, scan geometry, and cloud on measuring $\mathrm{CO}_{2}$ from space, J. Geophys. Res.-Atmos., 107, ACH 2-1-ACH 2-7, doi:10.1029/2001JD000618, 2002.

Rayner, P. J., Utembe, S. R., and Crowell, S.: Constraining regional greenhouse gas emissions using geostationary concentration measurements: a theoretical study, Atmos. Meas. Tech., 7, 3285-3293, doi:10.5194/amt-7-3285-2014, 2014.

Richter-Menge, J. A. and Farrell, S. L.: Arctic Sea Ice Conditions in Spring 2009-2013 Prior to Melt, Geophys. Res. Lett., 40, 58885893, 2013.

Richter-Menge, J. A. and Walsh, J. E. (Eds.): Seasonal-to-Decadal Predictions of Arctic Sea Ice: Challenges and Strategies, National Academies Press, Washington, DC, 2012.

Robards, M., Burns, J., Meek, C., and Watson, A.: Limitations of an optimum sustainable population or potential biological removal approach for conserving marine mammals: Pacific walrus case study, J. Environ. Manage., 91, 57-66, 2013.

Steele, M., Morley, R., and Ermold, W.: PHC: a global ocean hydrography with a high-quality Arctic ocean, J. Climate, 14, 2079-2087, 2001.

Stevens, D.: On open boundary condition in the united Kingdom Fine-Resolution Antarctic Model, J. Geophys. Res., 21, 1494 1499, 1991.

Sumata, H., Kauker, F., Gerdes, R., Köberle, C., and Karcher, M.: A comparison between gradient descent and stochastic approaches for parameter optimization of a sea ice model, Ocean Sci., 9, 609-630, doi:10.5194/os-9-609-2013, 2013.

Ziehn, T., Nickless, A., Rayner, P. J., Law, R. M., Roff, G., and Fraser, P.: Greenhouse gas network design using backward Lagrangian particle dispersion modelling - Part 1: Methodology and Australian test case, Atmos. Chem. Phys. Discuss., 14, 7557-7595, doi:10.5194/acpd-14-7557-2014, 2014. 